\title{
Optimization of Carbon and Nitrogen Sources for Extracellular Polymeric Substances Production by Chryseobacterium indologenes MUT.2
}

\author{
Mojtaba Khani ${ }^{1}$, Ali Bahrami 1*, Asma Chegeni ${ }^{1}$, Mohammad Davoud Ghafari ${ }^{2}$, ALi Mansouran Zadeh ${ }^{1}$ \\ ${ }^{1}$ Department of Bioscience and Biotechnology, Malek Ashtar University, Tehran, Iran \\ ${ }^{2}$ Young Researchers and Elites Club, North Tehran Branch, Islamic Azad University, Tehran, Iran \\ ${ }^{*}$ Corresponding author: Ali Bahrami, Department of Bioscience and Biotechnology, Malek Ashtar University, Tehran, Iran. Tel: +98-2122974599, \\ Fax: +98-2122974612, E-mail: a_bahrami@mut.ac.ir
}

Received: June 30, 2015; Revised: December 13, 2015; Accepted: February 15, 2016

Background: Bacterial Extracellular Polymeric Substances (EPS) are environmental friendly and versatile polymeric materials that are used in a wide range of industries such as: food, textile, cosmetics, and pharmaceuticals. To make the production process of the EPS cost-effective, improvements in the production yield is required which could be implemented through application of processes such as optimized culture conditions, and development of the strains with higher yield (e.g. through genetic manipulation), or using low-cost substrates.

Objectives: In this work, the effects of carbon and nitrogen sources were studied in order to improve the EPS production by the submerged cultivation of Chryseobacterium indologenes MUT.2.

Materials and Methods: The mesophilic microorganism Chryseobacterium indologenes MUT.2, was grown and maintained in the Luria Bertani agar. The initial basal medium contained: glucose $\left(20\right.$ g.L.-1), yeast extracts $\left(5\right.$ g.L $\left.\mathrm{L}^{-1}\right), \mathrm{K}_{2} \mathrm{HPO}_{4}$ $\left(6\right.$ g.L $\left.\mathrm{L}^{-1}\right), \mathrm{NaH}_{2} \mathrm{PO}_{4}\left(7\right.$ g.L $\left.\mathrm{L}^{-1}\right), \mathrm{NH}_{4} \mathrm{CL}\left(0.7\right.$ g.L $\left.\mathrm{L}^{-1}\right)$, and $\mathrm{MgSO}_{4}\left(0.5\right.$ g.L $\left.\mathrm{L}^{-1}\right)$. For evaluating the carbon and nitrogen sources' effect on the fermentation performance, cultures were prepared in $500 \mathrm{~mL}$ flasks filled with $300 \mathrm{~mL}$ of the medium. The single-factor experiments based on statistics was employed to evaluate and optimize the carbon and nitrogen sources for EPS production in the liquid culture medium of Chryseobacterium indologenes MUT.2.

Results: The preferred carbon-sources, sucrose and glucose, commonly gave the highest EPS production of 8.32 and 6.37 g.L $\mathrm{L}^{-1}$, respectively, and the maximum EPS production of 8.87 g.L $\mathrm{L}^{-1}$ was achieved when glutamic acid $\left(5\right.$ g.L $\left.\mathrm{L}^{-1}\right)$ was employed as the nitrogen source.

Conclusions: In this work, the culture medium for production of EPS by Chryseobacterium indologenes MUT.2 was optimized. Compared to the basal culture medium in shake-flasks and stirred tank bioreactor, the use of optimized culture medium has resulted in a $53 \%$ and $73 \%$ increase in the EPS production, respectively.

Keywords: Carbon source; Chryseobacterium indologenes; Extracellular polymeric substance; Medium composition; Nitrogen source; Stirred tank bioreactor

\section{Background}

Bacterial Extracellular Polymeric Substance (EPS) are environmental friendly polymeric materials that are used in a wide range of industrial applications (food, textile, cosmetics, pharmaceuticals, etc.) (1). Traditional EPS derived from other natural sources (i.e. plants, algae, and animals) fail to perform in some applications, in contrast, bacterial EPS may demonstrate new and improved properties. Furthermore, compared to synthesis of EPS by higher plants and algae, their microbial production is more productive and less resource-intensive. Moreover, microbial pro- duction enables the control of process conditions to obtain higher yields and desired properties (2). However, due to their high production costs, only a few bacterial EPS are commercially available (e.g. xanthan, gellan gum, hyaluronic acid). To make the process more cost-effective, improvements in the product yield is necessary, which, could be achieved through optimization of the culture condition, development of the high yield strains (e.g. through genetic manipulation), or application of the low-cost substrates (3). Nutritional and environmental conditions strongly affect microbial EPS' synthesis and composi- 
tion (4). Carbon and nitrogen sources generally play a significant role, because these nutrients are directly linked to the cell proliferation and metabolite biosynthesis $(5,6)$. Also, the nature and concentration of the carbon source can regulate the secondary metabolism through phenomena such as catabolic repression (7).

A number of statistical experimental design combined with the response surface methodology (RSM), such as factorial design, uniform design, Central Composite Design (CCD), and Box-Behnek Design (BBD) were applied for optimization of the fermentation conditions (1). M. Khani et al. (1) have used CCD for optimization of the operating parameters for EPS production by $C$. indologenes MUT.2. But, as far as we know, there is limited knowledge regarding nutritional requirement for EPS production by $C$. indologenes MUT.2. In addition, there hasn't been any report with respect to the medium optimization improvement for EPS production. C. indologenes MUT.2 was isolated from garden soil and hot spring water samples were collected from Arak city in Iran in order to investigate the corrosion inhibition by EPS. The EPS produced by the isolated $C$. indologenes MUT.2 was found to have high anti-corrosive properties (8). The electrochemical behavior of this new type of anti-corrosive EPS has been examined using electrochemical techniques and surface analytical examinations (FT-IR, EIS) (8). Both carbon and nitrogen sources were optimized in the present study by employing statistical method based on the single-factor experiments in order to improve the EPS production by $C$. indologenes MUT.2.

\section{Objectives}

In this study, for the first time, the effects of carbon and nitrogen sources were studied in order to improve the EPS production by submerged cultivation of $C$. indologenes MUT.2. The obtained information is considered to be fundamental and useful for development of the $C$. indologenes MUT.2 cultivation process, as well as an efficient production of the EPS on a laboratory scale stirred tank bioreactor.

\section{Materials and Methods}

\subsection{Microorganism and Inoculum Preparation}

The mesophile microorganism $C$. indologenes MUT.2 was kindly provided by the Biological Science and Technology Department, Malek Ashtar University, Tehran, Iran. The strain was maintained on nutrient agar at $4{ }^{\circ} \mathrm{C}$ and sub-cultured monthly. The strain was grown and maintained in LB-agar with the following composition: 5.0 g.L. $\mathrm{L}^{-1}$ sodium chloride, 5.0 g.L-1 yeast extract, 10.0 g.L.- tryptone, and 15.0 g.L-1 agar. During the preparation, the $\mathrm{pH}$ of the media was adjusted at 7.0 and then sterilized $\left(121^{\circ} \mathrm{C} / 15 \mathrm{~min}\right)$. Following to the $24 \mathrm{~h}$ of growth at $30^{\circ} \mathrm{C}$, the culture was maintained at $4^{\circ} \mathrm{C}(9)$.

Inoculum cultures were prepared in the LB-broth containing the following components as $\% \mathrm{~W} / \mathrm{W}$-final concentration: 0.5 sodium chloride, 1.0 tryptone, and 0.5 yeast extract (10). The $\mathrm{pH}$ of the medium was adjusted to the 7.0 before autoclaving $\left(121^{\circ} \mathrm{C} / 15 \mathrm{~min}\right)$. C. indologenes MUT.2 cells were inoculated in 250$\mathrm{mL}$ Erlenmeyer flasks containing $150 \mathrm{~mL}$ of LB-broth at $30 \pm 2^{\circ} \mathrm{C}$ for $24 \mathrm{~h}$. The flasks were placed in an orbital shaker (Tecnal model. TE-424, Tehran, Iran) at 170 rpm. Cell growth was monitored spectrophotometrically (PerkinElmer model Lambda 20) by measuring the optical density at $600 \mathrm{~nm}$ after $24 \mathrm{~h}$ of incubation until the cell count has reached $10^{7} \mathrm{CFU} \cdot \mathrm{mL}^{-1}$.

\subsection{Culture Medium}

The initial basal medium used contained glucose (20 g.L $\left.{ }^{-1}\right)$, yeast extracts $\left(5\right.$ g.L $\left.\mathrm{L}^{-1}\right), \mathrm{K}_{2} \mathrm{HPO}_{4}\left(6\right.$ g.L $\left.\mathrm{L}^{-1}\right)$, $\mathrm{NaH}_{2} \mathrm{PO}_{4}\left(7\right.$ g.L $\left.\mathrm{L}^{-1}\right), \mathrm{NH}_{4} \mathrm{CL}\left(0.7\right.$ g.L $\left.\mathrm{L}^{-1}\right)$, and $\mathrm{MgSO}_{4}$ $\left(0.5\right.$ g.L $\left.\mathrm{L}^{-1}\right)$. The medium constituents and glucose were sterilized separately by autoclaving at $121^{\circ} \mathrm{C}$ for 15 min, and were mixed thoroughly before inoculation. The chemicals used in this study were of reagent grade.

\subsection{Carbon and Nitrogen Source Screening}

For evaluating the effect of carbon and nitrogen sources on fermentation performance, cultures were conducted in $500 \mathrm{~mL}$ shake flasks filled with $300 \mathrm{~mL}$ of the medium. Then, the bacterial pre-culture medium $(6 \%, \mathrm{~V} / \mathrm{V})$ was inoculated in the flasks and incubated for $96 \mathrm{~h}$. The flasks were held at $30^{\circ} \mathrm{C}$ on a rotary shaker at $170 \mathrm{rpm}$.

\subsection{Fermentation Conditions}

The fermentation medium was inoculated with $6 \%$ $(\mathrm{V} / \mathrm{V})$ of the seed culture and then cultivated at $30^{\circ} \mathrm{C}$ in a 3 liter stirring tank bioreactor (Bioflow III, New Brunswick Scientific Co., New Brunswick, NJ, USA). Unless otherwise specified, fermentation were conducted under the following condition: temperature at $30^{\circ} \mathrm{C}$, aeration rate $1.0 \mathrm{vvm}$, agitation speed $250 / \mathrm{min}$, the initial $\mathrm{pH} 7.0$, and the working volume 21 .

\subsection{Analysis of Biomass}

The bacterial dry cell biomass was collected by 
centrifuging $1 \mathrm{~mL}$ culture samples at $11000 \mathrm{~g}$ for 10 min (Sigma 1-16K, No.12134). The centrifuged cell pellet was washed twice with distilled water and dried at $80^{\circ} \mathrm{C}$ in an oven for $24 \mathrm{~h}$ to obtain cell dry weight (CDW). CDW was calculated using a gravimetric method and was expressed as g.L-1.

\subsection{Analysis of EPS}

Mycelial pellets were separated by centrifugation (Sigma 6-16K, No.12256) at $16000 \mathrm{~g}$ for $10 \mathrm{~min}$ and the supernatant was mixed with three volumes of the chilled absolute ethanol to precipitate the EPS. The sample solutions were stored at $4^{\circ} \mathrm{C}$ for $24 \mathrm{~h}$ to enhance the precipitation. Finally, the EPS were recovered by centrifugation at $9000 \mathrm{~g}$ for $15 \mathrm{~min}$ and dried at room temperature. EPS production was calculated using a gravimetric method and was expressed as g.L-1

\section{Results}

\subsection{Effect of Carbon Sources}

The following set of experiments were done in order to investigate the effects of the various types of carbon sources on the cell growth of $C$. indologenes MUT.2 and production of EPS. In all cases, nitrogen was provided as yeast extract at the same concentration that was used in the basal medium, where each carbon source was added to the basal medium at 20 g.L.-1 instead of glucose. (Figure 1) shows the time profile of the biomass concentration (A) and EPS production (B) for the cultures carried out with all different types of the tested carbon sources as well as the culture without addition of the any type of carbon source as the control. The results obtained from shake-flask experiments revealed that, the change in the employed
Table 1. The effect of the different carbon sources on C. indologenes MUT.2 growth and extracellular polymeric substance (EPS) production during cultivation in the shake-flasks for $96 \mathrm{~h}$ at $30^{\circ} \mathrm{C}$. The highest cell mass, EPS and other related factors were observed when sucrose was used a carbon source

\begin{tabular}{lcccc}
\hline $\begin{array}{l}\text { Carbon } \\
\text { sources }\end{array}$ & $\begin{array}{c}\text { Dry cell } \\
\text { weight }\left(\mathbf{g} \cdot \mathbf{L}^{-1}\right)\end{array}$ & EPS (g.L-1) & EPS/CDW & Final pH \\
\hline Control $^{\star}$ & 0.41 & 0.22 & 0.53 & 7.28 \\
Xylose & 1.32 & 5.63 & 4.26 & 6.53 \\
Galactose & 1.40 & 3.58 & 2.55 & 6.64 \\
Glycerol & 1.48 & 6.08 & 4.10 & 6.32 \\
Glucose & 1.52 & 6.37 & 4.19 & 6.15 \\
Fructose & 1.29 & 4.96 & 3.84 & 6.81 \\
Maltose & 1.56 & 2.37 & 1.50 & 6.94 \\
Sucrose & 1.85 & 8.32 & 4.49 & 5.98 \\
Lactose & 1.37 & 4.12 & 3.00 & 6.56 \\
Mannose & 1.05 & 2.51 & 2.39 & 7.17 \\
Starch & 0.98 & 2.07 & 2.11 & 7.35 \\
Dextrin & 1.12 & 3.15 & 2.81 & 7.22 \\
\hline
\end{tabular}

${ }^{*}$ Control culture without any carbon source

carbon source has affected both the amount of the produced biomass and the EPS production. Although galactose, maltose, and lactose gave good mycelial growth, they led to low EPS yields. The preferred carbon sources; sucrose and glucose, generally resulted in the highest EPS production of 8.32 and 6.37 g.L $\mathrm{L}^{-1}$, respectively as shown in (Table 1).

\subsection{Effect of the Nitrogen Source}

To investigate the effect of the nitrogen source on EPS production and mycelial growth, eight different nitrogen sources ( $\mathrm{N}$ source) were examined (Figure 2). These N-sources were added on the basis of an equivalent N-content. Although yeast extract and glycine
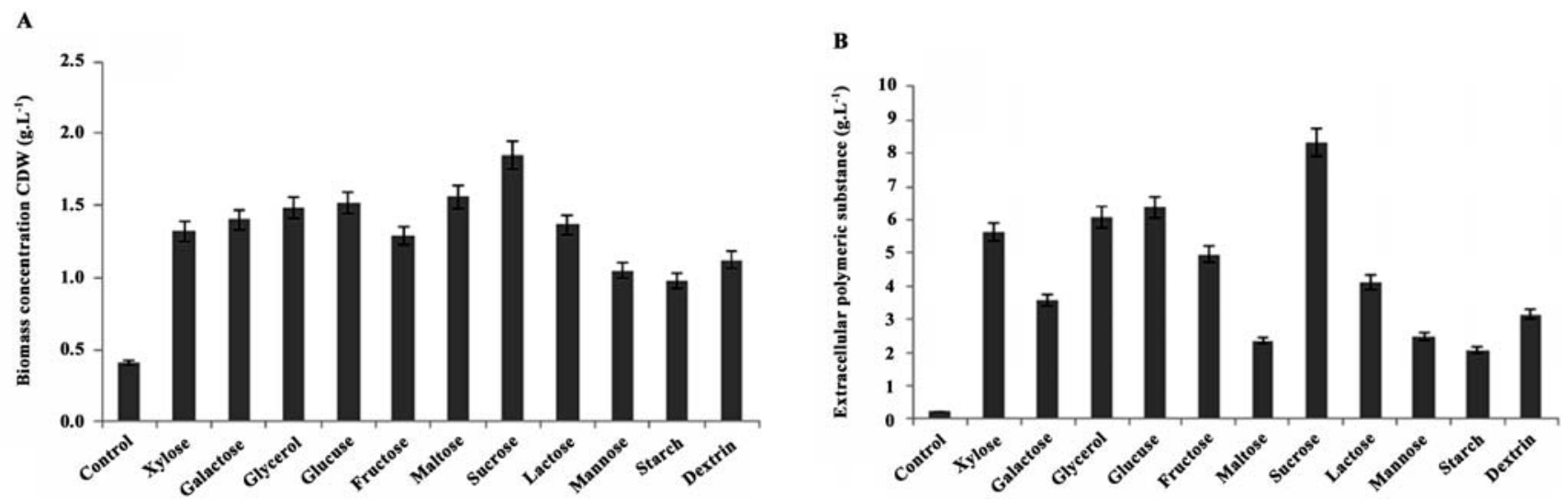

Figure 1. A: The effect of different carbon sources on the cell growth of $C$. indologenes MUT.2 and B: EPS production after 96 h of cultivation. sucrose was found to have the best effect on EPS production 

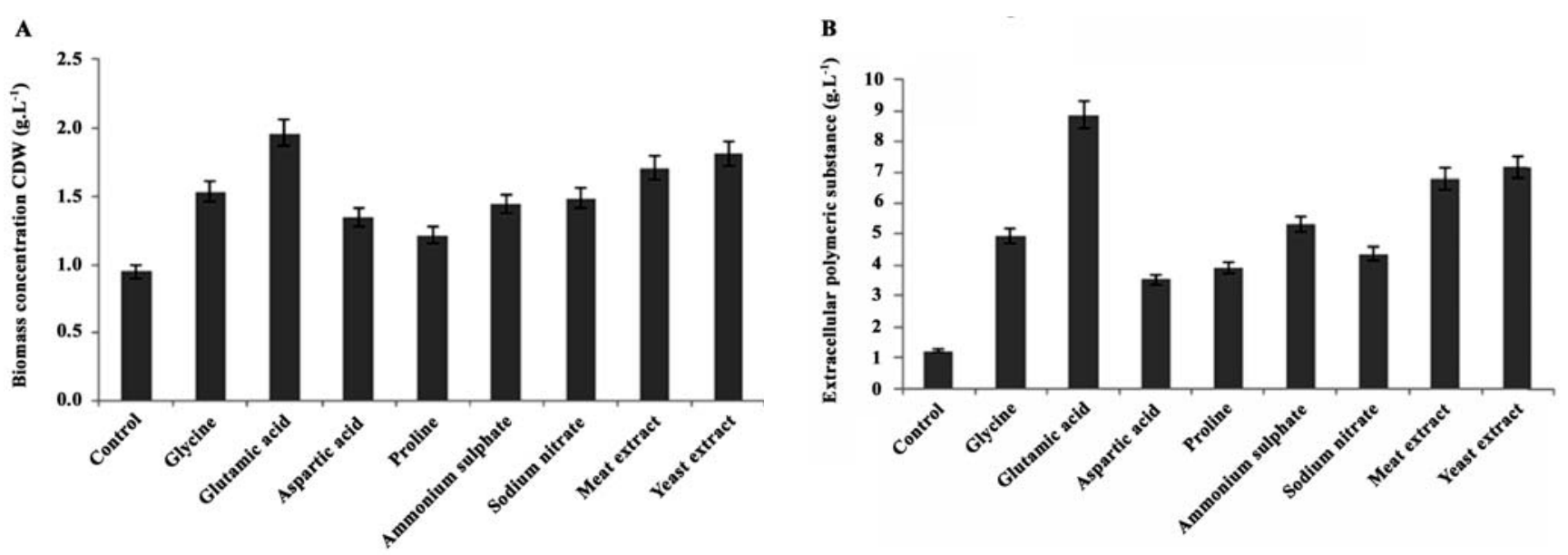

Figure 2. A: Effect of the different nitrogen sources on the C. indologenes MUT.2 cell growth and B: EPS production following 96 h of cultivation. Glutamic acid was found to have the best effect on EPS production

were favorable for the mycelial growth of the $C$. indologenes, the maximum EPS production of 8.87 g.L $\mathrm{L}^{-1}$ was achieved when glutamic acid $\left(5\right.$ g.L $\left.\mathrm{L}^{-1}\right)$ was employed (Figure 2B). Improvement in the cell growth, EPS production, and EPS/CDW ratio through application of the different nitrogen sources are summarized in (Table 2).

\subsection{Cultivation of C. indologenes MUT.2 in Shake-} Flasks with the Optimized Medium

Using all optimized medium components, trials in a series of the shake-flasks was done using 20 g.L-1 sucrose as the carbon source and 5 g.L $\mathrm{L}^{-1}$ glutamic acid as nitrogen source. The time course of the cell growth,

Table 2. The effect of the different nitrogen sources on the $C$. indologenes MUT.2 growth and its extracellular polymeric substance (EPS) production during cultivation in shake-flasks for 96 hours at $30^{\circ} \mathrm{C}$. The highest cell mass, EPS and other related factors were observed when glutamic acid was used as nitrogen source

\begin{tabular}{lcccc}
\hline $\begin{array}{l}\text { Nitrogen } \\
\text { sources }\end{array}$ & $\begin{array}{c}\text { Dry cell } \\
\text { weight }\left(\mathbf{g} \cdot \mathbf{L}^{-1}\right)\end{array}$ & EPS $\left(\mathbf{g} \cdot \mathbf{L}^{-1}\right)$ & EPS/CDW & Final $\mathbf{p H}$ \\
\hline Control* & 0.95 & 1.21 & 1.27 & 6.07 \\
Glycine & 1.53 & 4.95 & 3.23 & 6.51 \\
Glutamic acid & 1.96 & 8.87 & 4.52 & 6.61 \\
Aspartic acid & 1.34 & 3.51 & 2.61 & 6.38 \\
Proline & 1.21 & 3.92 & 3.23 & 5.96 \\
Ammonium & 1.44 & 5.32 & 3.69 & 5.81 \\
sulphate & & & & \\
& & & & \\
Sodium nitrate & 1.48 & 4.35 & 2.93 & 5.49 \\
Meat extract & 1.70 & 6.78 & 3.98 & 6.32 \\
Yeast extract & 1.81 & 7.17 & 3.96 & 6.41 \\
\hline
\end{tabular}

${ }^{*}$ Control culture without any nitrogen source
EPS production, and $\mathrm{pH}$ values are shown in (Figure 3). The maximal EPS production was achieved as: 8.9 g.L. $\mathrm{L}^{-1}$ after 3.5 days of the fermentation, while, the maximum mycelial yield was about 1.96 g.L.-1 achievable after 3.5 days. This indicates a 53\% increase in the EPS production using the optimized medium $\left(8.9\right.$ g.L $\left.\mathrm{L}^{-1}\right)$ compared to EPS production using the basal medium (5.8 g. $\left.\mathrm{L}^{-1}\right)$, as previously described. In addition, similar increase in the biomass concentration was achieved using the optimized medium.

\subsection{Fermentation in the Stirring Tank Bioreactor}

Although shake flasks are the most frequently used bioreactors in biotechnology for an initial process development, very little is known regarding their characteristics from an engineering point of view $(11,12)$. There are several reports in the literature regarding the scaling-up of processes from the shake flasks to the

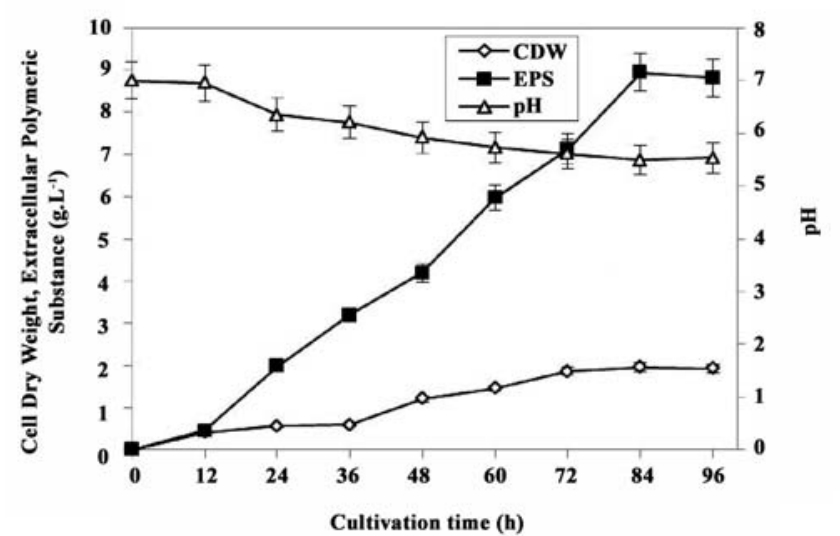

Figure 3. Batch cultivation of the $C$. indologenes MUT.2 in the shake flasks using the optimized medium 
stirred tank bioreactors $(13,14)$. Therefore, the bioreactor fermentation process was developed on the basis of data obtained from shake flasks cultivation experiments. The production of EPS was studied in a 3 liter bioreactor using the basal and the optimized culture medium.

Figure 4 shows the time courses of mycelial growth and EPS production by $C$. indologenes MUT. 2 in a 3 liter stirred tank fermenter with the basal medium and the optimized culture medium. In the basal medium, the EPS concentration reached a maximum level of 5.84 g.L $\mathrm{L}^{-1}$ after 3 days, while, maximum mycelial concentration was 1.59 g.L $\mathrm{L}^{-1}$ after 3 days (Figure 4A). In an optimized culture medium as shown in (Figure 4B), the mycelial growth was continuously increased towards the end of fermentation and its final mycelial concentration has indicated an amount of almost 1.98 g. $\mathrm{L}^{-1}$ at day 3.5. The initial $\mathrm{pH}$ of the fermentation broth slowly decreased from 7.00 to 5.02 . The EPS production reached 10.15 g.L.-1 after 3.5 days of the

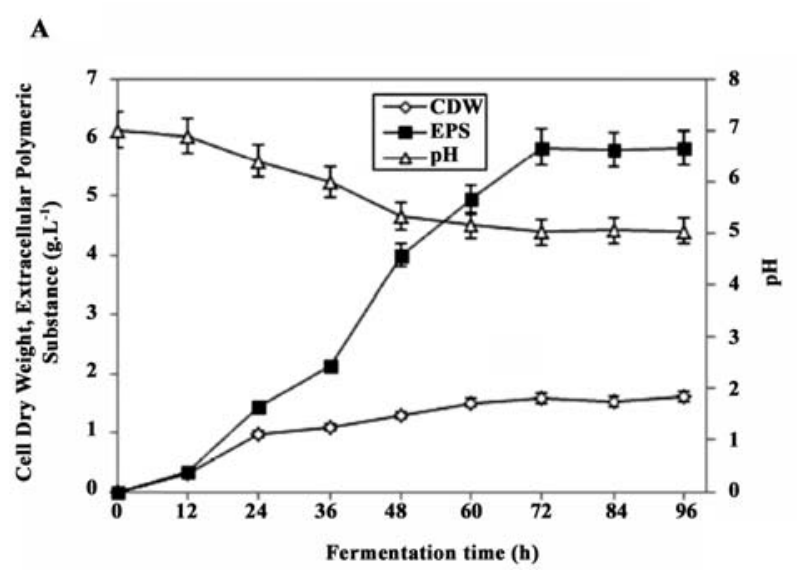

B

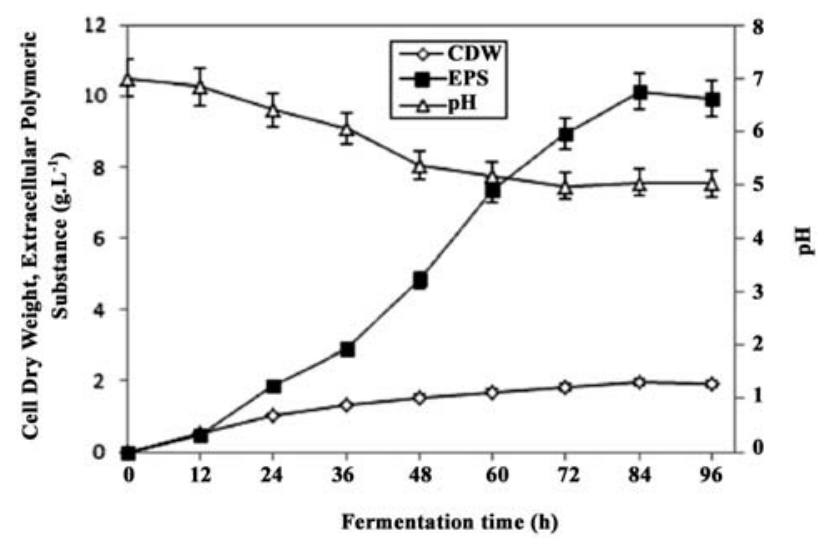

Figure 4. A: Batch fermentation of the $C$. indologenes MUT.2 in the stirred tank bioreactor in the presence of the basal medium and $\mathrm{B}$ : in the optimized medium fermentation, which is 1.7 times higher than that of fermentation in the basal medium. Optimization of the operating parameters (e.g. agitation, aeration, and dissolved oxygen tension) in the bioreactor fermentation deserves further investigation, which is being carried out in our laboratory.

\section{Discussion}

The results obtained in the present study are in agreement with the general concept expressed in the early studies $(15,16)$ which have reported the highest exopolysaccharides yield using fructose, sucrose, and glucose as carbon sources. Recently, Zhang et al. (17), studied the production of gellan exopolysaccharide by growing strains of Sphingomonas paucimobilis QHZJ UJW in the medium containing various carbon sources such as glucose, sucrose, maltose, malt extract powder, and vegetable oil. They found that the highest EPS production of the strain in the sucrose containing medium. Qiang et al. (18) have used RSM for EPS production by Klebsiella sp. H-207, isolated from activated sludge. A maximum EPS yield of about 15.05 g.L $\mathrm{L}^{-1}$ was achieved under optimized conditions in terms of both the medium composition and culture condition, which consisted of sucrose 31.93 g.L.-1, $\mathrm{KNO}_{3} 2.17$ g.L $\mathrm{L}^{-1}$ and $\mathrm{K}_{2} \mathrm{HPO}_{4} 5.47$ g.L-1, a seed age of $13 \mathrm{~h}$, with an inoculum size of $10.6 \%$ and an incubation temperature of $28.9^{\circ} \mathrm{C}$. Screening of the most significant fermentation parameters affecting levan production was done by the statiscal designs for the microbial strain Pseudomonas fluorescens NCIM 2059. Six nutritional variables (i.e. sucrose, casein peptone, $\mathrm{NH}_{4} \mathrm{Cl}, \mathrm{KH}_{2} \mathrm{PO}_{4}, \mathrm{MgSO}_{4}$, and $\mathrm{NaNO}_{3}$ ) were studied to define an optimal medium. A significant increase in the levan yield from 5.27 up to 15.42 g.L $\mathrm{L}^{-1}$ under these conditions was found (19). In a recent study, a novel bacterium strain BM39, associated with Pantoea sp., was isolated from sediments of Tyrrhenian Sea. The strain was selected for its ability to produce a very high levels of the glucan EPS. Kinetic studies of EPS production by the strain BM39 cultivated in the shaken cultures using a medium containing 80 g.L $\mathrm{L}^{-1}$ of sucrose (EMS medium) and 80.0 g.L $\mathrm{L}^{-1}$ of fructose (EMF medium) as carbon sources, was shown an EPS production the amounts of which was estimated as $11.82 \pm 1.06$ g.L.-1 and $11.05 \pm 1.17$ g.L $\mathrm{L}^{-1}$, respectively, while the productivity was $0.39 \pm 0.04$ g.L $\mathrm{L}^{-1} . \mathrm{h}$ and $0.37 \pm 0.04$ g.L $\mathrm{L}^{-1} \cdot \mathrm{h}^{-1}$ (20). Bounaix et al. (21) have clearly demonstrated a high biodiversity of EPS produced by sourdough LAB strains with sucrose substrate (21).

In this work, culture medium for production of EPS by $C$. indologenes MUT.2 was optimized. Compared 
with the basal culture medium in shake-flasks and stirred tank bioreactor, the use of optimized culture medium has resulted in a $53 \%$ and $73 \%$ increase in EPS production, respectively. No reports are currently available in the literature regarding the optimization of the extracellular polymeric substance production by $C$. indologenes MUT.2 in the submerged culture. Our study provides an important information for the largescale production of the bioactive natural products such as EPS by C. indologenes MUT.2, which can be used as an functional anti-corrosive.

\section{Acknowledgements}

Authors would like to thank Department of Bioscience and Biotechnology Malek Ashtar University for the financial support to this study.

\section{References}

1. Khani M, Bahrami A, Ghafari MD. Optimization of operating parameters for anti-corrosive biopolymer production by Chryseobacterium Indologenes MUT. 2 using central composite design methodology. J Taiwan Inst Chem Eng. 2015. DOI: 10.1016/j.jtice.2015.09.016

2. Alves VD, Freitas F, Torres CA, Cruz M, Marques R, Grandfils $\mathrm{C}$, et al. Rheological and morphological characterization of the culture broth during exopolysaccharide production by Enterobacter sp. Carbohydr Polym. 2009. DOI: 10.1016/j.carbpo 1.2009.09.006

3. Freitas F, Alves VD, Reis MA. Advances in bacterial exopolysaccharides: from production to biotechnological applications. Trends Biotechnol Res. 2011;29(8):388-398. DOI: 10.1016/j.tibtech.2011.03.008

4. Suresh Kumar A, Mody K, Jha B. Bacterial exopolysaccharides-a perception. J Basic Microbiol. 2007;47(2):103-117. DOI: $10.1002 /$ jobm.200610203

5. Kim SW, Xu CP, Hwang HJ, Choi JW, Kim CW, Yun JW. Production and Characterization of Exopolysaccharides from an Enthomopathogenic Fungus Cordycepsmilitaris NG3. Biotechnol Prog. 2003;19(2):428-435. DOI: 10.1021/bp $025644 \mathrm{k}$

6. Lopez JC, Pérez JS, Sevilla JF, Fernandez FA, Grima EM, Chisti Y. Production of lovastatin by Aspergillus terreus: effects of the $\mathrm{C}: \mathrm{N}$ ratio and the principal nutrients on growth and metabolite production. Enzyme Microb Technol. 2003;33(2):270-277. DOI: 10.1016/S0141-0229(03)00130-3

7. Görke B, Stülke J. Carbon catabolite repression in bacteria: many ways to make the most out of nutrients. Nat Rev Microbiol. 2008;6(8):613-624. DOI: 10.1038/nrmicro1932

8. Ghafari M, Bahrami A, Rasooli I, Arabian D, Ghafari F. Bacterial exopolymeric inhibition of carbon steel corrosion. Int Biodeterior Biodegradation. 2013;80:29-33. DOI: 10.1016/j.ibiod.2013.02. 007

9. Galindo E, Salcedo G, Ramírez ME. Preservation of Xanthomonas campestris on agar slopes: effects on xanthan production. Appl Microbiol Biotechnol. 1994;40(5):634-637. DOI: $10.1007 / \mathrm{BF} 00173320$
10. Garcýa-Ochoa F, Santos V, Casas J, Gomez E. Xanthan gum: production, recovery, and properties. Biotechnol Adv. 2000;18(7):549-579. DOI: 10.1016/S0734-9750(00)00050-1

11. Büchs J. Introduction to advantages and problems of shaken cultures. Biochem Eng J. 2001;7(2):91-98. DOI: 10.1016/S1369-703X(00)00106-6

12. Suresh S, Srivastava V, Mishra I. Critical analysis of engineering aspects of shaken flask bioreactors. Crit Rev Biotechnoly. 2009;29(4):255-278. DOI: 10.3109/07388550903062314

13. Garcia-Ochoa F, Gomez E. Bioreactor scale-up and oxygen transfer rate in microbial processes: an overview. Biotechnol Adv. 2009;27(2):153-176. DOI: 10.1016/j.biotechadv.2008. 10.006

14. Reyes C, Peña C, Galindo E. Reproducing shake flasks performance in stirred fermentors: production of alginates by Azotobacter vinelandii. J Biotechnol. 2003;105(1):189-198. DOI: 10.1016/ S0168-1656(03)00186-X

15. Kornmann H, Duboc P, Marison I, von Stockar U. Influence of nutritional factors on the nature, yield, and composition of exopolysaccharides produced by Gluconacetobacter xylinus I-2281. Appl Environ Microbiol. 2003;69(10):6091-6098. DOI: 10.1128/AEM.69.10.6091-6098.2003

16. Bueno SM, Garcia-Cruz CH. Optimization of polysaccharides production by bacteria isolated from soil. Braz J Microbiol. 2006;37(3):296-301. DOI: 10.1590/S1517-838220060003 00018

17. Zhang J, Dong YC, Fan LL, Jiao ZH, Chen QH. Optimization of culture medium compositions for gellan gum production by a halobacterium Sphingomonas paucimobilis. Carbohydr Polym. 2015;115:694-700. DOI: 10.1016/j.carbpol.2014.09. 029

18. Qiang L, Yumei L, Sheng H, Yingzi L, Dongxue S, Dake H, et al. Optimization of fermentation conditions and properties of an exopolysaccharide from Klebsiella sp. H-207 and application in adsorption of hexavalent chromium. PLOS ONE. 2013;8(1):e53542. DOI: 10.1371/journal.pone.0053542

19. Jathore NR, Bule MV, Tilay AV, Annapure US. Microbial levan from Pseudomonas fluorescens: Characterization and medium optimization for enhanced production. Food Sci Biotechnol. 2012;21(4):1045-1053. DOI: 10.1007/s10068-012-0136-8

20. Silvi S, Barghini P, Aquilanti A, Juarez-Jimenez B, Fenice M. Physiologic and metabolic characterization of a new marine isolate (BM39) of Pantoea sp. producing high levels of exopolysaccharide. Microb Cell Fact. 2013;12(1):10. DOI: 10.1186/1475-2859-12-10

21. Bounaix M-S, Gabriel Vr, Morel S, Robert H, Rabier P, Remaud-Sime' on $\mathrm{M}$, et al. Biodiversity of exopolysaccharides produced from sucrose by sourdough lactic acid bacteria. J Agric Food Chem. 2009;57(22):10889-10897. DOI: 10. 1021/jf902068t 